\title{
Annual activity report - measuring the results of the editorial team
}

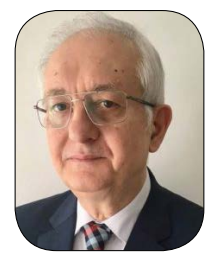

Marian-Vladimir CONSTANTINESCU

DDS, MSc, PhD, Professor

Editor-in-Chief

Dear readers, Dear authors,

Measuring the passage of time is, more often than not, a difficult, challenging occupation. The attempt is all the more interesting as we are looking at a project in which we are totally involved.

Dental professionals in Central and Eastern Europe have limited acccess to listed jourals in order to publish their research so as improve their academic standing, and this motivated and determined me to create a new specialized journal.

In the academic environment, more than 1.8 million dentists worldwide ${ }^{1}$ come from 13,711 higher education institutions (WHO, 2019) ${ }^{2}$ and there are 20,164 titles for oral science, 1,630 titles for oral health and 155 titles in the DENTISTRY category, as well as in ORAL SURGERY \& MEDICINE, listed in the Master Journal List (Web of Science, 2020) ${ }^{3}$.

Let's go through the evolution of the Stomatology Edu Journal (Stoma Edu J) as of the spring of 2013 when we invited Prof. Jean-François Roulet from the University of Florida, USA to take over the coordination of the journal. My request was supported by the fact that he is a renowned researcher and in time has coordinated several such journals as Editor-in-Chief (EiC).

When the first issue of Stoma Edu J was ready, I sent it to be evalauted by the EiC who certifies the quality of the publication, Prof. J-F. Roulet. Each article went through the double-blind review process. That is, it travelled the following course: strict evaluation by two or more reviewers experts in the field approached by the article; the manuscript modified by the authors as a result of the reviewers' recommendations went through the language proofreading by our specialized editor, interpreter and translator certified by the European Institutions, Prof. Roxana Cristina Petcu. The linguistically corrected WORD document is formatted in PDF. The PDF form of the journal is submitted for analysis and final proofreading to the EiC, responsible for the quality of the publication.

The answer I got was, as always, very kind and to the point with reference to each document.

There came a difficult exercise with seven rounds of proofreading, but we finally managed to get some signal copies to be presented to colleagues participating in the 101st FDI Annual World Dental Congress, 28-31 August 2013, Istanbul, Turkey.

After attending a lecture delivered by Prof. Anton Sculean from the University of Bern, I presented him with the journal. He immediately noticed the abstract both in Romanian and English. After expressing his support and acceptance to be a member of the Editorial Board of the journal, he recommended that for it to be successfull, we must delete the Romanian version of the abstract. It was very difficult for me to accept this decision to delete that part in the language of our national poet, Mihai Eminescu.

This editorial process was followed rigorously and consistently to complete each issue until December 2018. Then, making use of his own personal resources, Prof. J-F. Roulet decided to introduce the Manuscript Manager platform (www.manuscriptmanager.com) ${ }^{4}$ in the Stoma Edu J's editorial process. Thus, as of the 2019 first issue of 2019, it was this platform that managed the submission of the manuscripts and all the peerreview process until all the manuscripts were accepted for publication, ie via "transparency in peer review" 
All manuscripts of journals published by Quintessence Publishing, Wiley, Thieme and other recognized publishers use this platform, so over 250 academic journals all over the world.

From the very beginning, since we started publishing the Stoma Edu J, I have aimed towards high standards of quality, attracting articles, performing the final proofreading and the timely publication of each issue. In October 2019, due to the delayed peer-review process, I was notified by Prof. J-F. Roulet and Prof. N. Ilie that the first 2020 issue to be published on March 31 could only be published at the beginning of June 2020 . Given the situation, I wrote a letter to all the Stoma Edu J editors asking if a correct peer-review process could be performed in only 2-3 weeks and NOT 3 months. My approach was justified by the practice of IEEE Access, a journal that requests a review in only 7 days, a request to which I have repeatedly responded. Most respondents confirmed that a correct process can be completed in 2-3 weeks.

Following my last intervention, In November 2019, Prof. J-F. Roulet and Prof. N. llie sent me a common letter, warning me that as a result of my constant pressure to publish the latest issues with their extreme efforts, they jointly decided to withdraw from the management of the platform.

In view of the timely publication of the first 2020 issue, I consulted my good friend, the famous oro-maxillofacial surgeon Prof. Constantinus Politis of the University of Leuven, Belgium to find a realistic solution to manage the editorial managerial crisis. Therfore, we decided to restructure the Editor-in-Chiefs' team. First, for his exceptional merits and venerable age, we decided that Prof. Rolf Ewers of the Medical University of Vienna, Austria, should enhance the Senior Editors' team.

Against this backdrop, Prof. Constantinus Politis accepted the vacant position of Editor-in-Chief. Following my repeated requests addressed to my good friend, the oro-maxillo-facial surgeon, Prof. Gavriel Chaushu of Tel Aviv University, Israel, he generously agreed to take up the decisive position of administrator of the Manuscript Manager platform.

For her merits as a researcher in the field of dental biomaterials, Prof. Mutlu Özcan from the University of Zürich, Switzerland completed the team of Co-Editors-in-Chief (Europe). We still had to fill the position of $\mathrm{EiC}$ with notable skills in restorative dentistry, dental materials and in managing the quality of a specialized journal. Together with Prof. Constantinus Politis, we approached all the academic staff at the University of Leuven, Belgium, then, for more than three months, we contacted various other experts worldwide, but without any concrete results.

At the end of this investigation, I remembered Prof. Marco Ferrari, Dean of the University of Siena, Italy, whose conference I attended during the 106th edition of the FDI World Dental Congress in Buenos Aires, Argentina, 5-8 September 2018. Following my warm invitation to accept the position of EiC and due to the perseverance of my friend Prof. Letizia Perillo, Dean at the University of Campania Luigi Vanvitelli, Naples, Italy, Prof. Marco Ferrari agreed to take over the scientific coordination of the Stoma Edu J. On June 13, 2018, I registered the Stoma Edu J at Clarivate Analytics to have it evaluated according to the 18 criteria.

The American evaluator appointed to assess our journal left the company after a few months and did not complete the evaluation. Meanwhile, the company has increased its level of exigency to a 24 criteria-based evaluation. Because of a lack of administrative synchronization, we have become the beneficiaries of a 24 criteria-based evaluation!

In April 2020, I received the recommendation that each author should be more visible. That is, each author should mention, in addition to his/her education and degrees, as well as his/her institutional affiliation, his/her e-mail, preferably the institutional one, and the registration in ORCID, ie ORCIDiD. Although all this information is requested by the Manuscript Manager platform, few authors rigorously complete this information. Thus, in order to fill this information gap, we created a table on the research profile of each author. Thus, once the proof is sent for correction and it is approved, the corresponding author is requested to fill in this table. Such information allows the reader of each article to better know the scientific contribution of each author.

In November 2020, the evaluator Clarivate Analytics informed us that the Stoma Edu J was still under evaluation, and would receive the evaluation only after Clarivate Analytics had completed the still pending updating of the listed journals. With a complete team, in a more dynamic formula, in 2020 we decided to certify the quality of our publication. The subsequent evolution of the Stoma Edu J comes to contradict Umberto Eco's statement in The Name of the Rose: "After so many years even the fire of passion dies, and with it what was believed the light of truth". First, as shown by the current practice of certified and listed journals, we managed to have each document presented in three variants, JATS-XML, HTML and PDF. Valentin Miroiu, our technical editor, started doing it with the third 2020 issue, going backwards to the first 2018 issue, when the registration was made with Clarivate Analytics.

As a result of the determined, energetic and active involvement of the platform administrator, Prof. Gavriel Chaushu, we would like to mention that, remarkably, each 2020 issue was published before the deadline, 
while also having the DOls activated by Crossref. The new team of Editor-in-Chiefs comes before you, the readers, with a series of achievements. First of all, after 5 years of evaluation, we managed, on May 5, 2020, to conclude an Amendment to License Agreement with President Tim Collins of EBSCO Publishing, Inc. We don't know if this is an achievement for you, authors and readers, but for us it certainly meant an important stage on the Stoma Edu J's roadmap.

I'm sure that for the subsequent listing of the journal, it may not be a top achievement, but for us it means was areal achievement to enter an Amendment with the President of a Publishing House that has more than 3,250 employees and annual sales of more than two billion dollars.

The databases for journals like the Stoma Edu J mention under the Dimensions section 375 publications, 168 citations, with a citation mean 0.45, a Google Scholar 130 citations, h-index 6, i10-index 4, and Scilit a total of approximately 257 articles. Since December 2020 the Stoma Edu J has been under evaluation by Scopus and in the re-evaluation procedure at the Directory of Open Access Journals (DOAJ).

Given the very trying times that we are going through, I feel obliged to mention to you the premature death of three friends of the Stoma Edu J, namely Prof. Alexandru Simion Ogodescu, from the "Victor Babes" University of Medicine and Pharmacy Timisoara, Romania, Editor-in-Chief of the Orthodontics and DentoFacial Section, Dr. loan Opriș Associate Scientist, University of Miami, USA, as Honorary Statistical Adviser, and Acad. Alexandru Surdu, President of the Philosophical, Theological, Psychological and Pedagogical Sciences Section, Director of the Institute of Philosophy and Psychology "Constantin Rădulescu-Motru" of the Romanian Academy, a prominent figure in the Romanian philosophy and culture.

On behalf of the Executive Editorial Board of the Stoma Edu J, please allow me to wish you and your loved ones a blessed Christmas, a happy New Year and to fully enjoy peace, health, well-being and joy in your homes.

Sincerely yours,

Marian-Vladimir Constantinescu ${ }^{\circ}$

Editor-in-Chief

\section{References}

1. https://apps.who.int/gho/data/node.main.HWF

2. https://www.who.int/research-observatory/monitoring/inputs/WHED/en/

3. https://mjl.clarivate.com/search-results

4. https://manuscriptmanager.com/

5. Roulet JF. Transparency in peer review. Stoma Edu J. 2019; 6 (1): 4. 